\title{
Development of Water in Olive Oil (W/O) Nanoemulsions as Lipstick Base Formulation
}

\author{
Siti Z. Munawiroh ${ }^{1,2}$, Aughina N. Nabila ${ }^{1}$, and Lutfi Chabib ${ }^{1,2}$ \\ ${ }^{1}$ Department of Pharmacy, Faculty of Mathematics and Natural Sciences, Universitas Islam Indonesia, Yogyakarta, \\ Indonesia \\ ${ }^{2}$ Nanofabrication Research Center, Laboratory of Technology Pharmacy, Department of Pharmacy, Universitas Islam \\ Indonesia, Yogyakarta, Indonesia \\ Email: sitizahliyatul@uii.ac.id
}

\begin{abstract}
Objective: The objective of this research is to develop w/o olive nanoemulsions which prepared by low energy method to use in lipstick base formulation. Methods: W/O olive nanoemulsions were prepared by low energy methods which was employed a Phase Inversion Composition (PIC) technique in elevated temperature at $80^{\circ} \mathrm{C}$ using mixed-surfactants (tween 20 /span 80). Results: In ternary phase diagram (oil:water:mixed-surfactants), the largest area of nanoemulsions was occurred in equal ratio tween20:span80 (1:1). The maximum water content of w/o olive nanoemulsions was reached at $12 \%$ water with $60 \%$ mixed-surfactants (1:1). An unimodal size distribution of w/o olive nanoemulsions with varied water content at 8,10 and $12 \%$ were found with droplet size at $29.33 \pm 5.30 \mathrm{~nm}$, $30.23 \pm 7.33 \mathrm{~nm}$ and $29.83 \pm 11.47 \mathrm{~nm}$. Water content of w/o olive nanoemulsions significantly affected to melting profile of lipstick but not to the hardness properties of lipstick. Conclusion: W/O olive nanoemulsions which prepared by low energy can be developed as lipstick base formulation.
\end{abstract}

Index Terms - w/o nanoemulsions, low energy, olive oil, lipstick

\section{INTRODUCTION}

Lipstick has been used by human since 500 years ago. In the early days of lipstick discovery, in ancient Mesopotamia, lipstick was still a rough fragment of brick that used to coloring lips [1]. Then in France (1869), lipstick was introduced as cosmetic which prepared from animal fat and wax from bees [2]. Recently, lipstick as decorative cosmetics is made from a combination of wax and oil (anhydrous). But lately, Lipstick is not only for coloring lips but also as moisturizing or even been used as a drug delivery through the skin of the lips [3], [4].

Related to function as a moisturizing lipstick, water is the basic ingredient for moisturizing the lips. For medication purpose, sometimes hydrophilic active compounds have to in lipstick formulation. The addition of water or hydrophilic materials on lipstick becomes constrained due to the basic components of lipstick is hydrophobic. The system of water-in-oil emulsion is the solution to overcome this problem. Several experiments have been conducted to manufacture lipstick by adding

Manuscript received February 16, 2016; revised March 30, 2017. water in oil emulsions [5], [6]. However, the addition of water emulsified in the preparation of lipstick still leave some problems for example discoloration, less homogeneous mixing of the components of lipstick, the discharge of water from the droplet at the time of molding and changing physical properties, undesirable brittle and hardness [7]. Water in oil emulsion system, lipstick can only hold water or hydrophilic materials as much as $2 \%$. Water-in-oil (w/o) nanoemulsions which is a kinetically stable dispersion has been employed to overcome this problem. W/O nanoemulsions system was found to increase the amount of water added up to $10 \%$ [8]. However, the use of high energy (high pressure homogenizer) in the manufacture of nanoemulsions produces less uniform nanoemulsions and high investment costs for the equipment. Therefore, it still needs to investigate on the development of w/o nanoemulsions that will be used as components of the preparation lipstick using low energy.

In this research, the development of w/o nanoemulsions is conducted by low energy with olive oil as model of oil phase. The characteristics of w/o olive nanoemulsions were determined by particle size and polydispersity index. 3 selected formulations of w/o nanoemulsions were further investigated their water content effect on physical characteristic of lipstick. Conventional lipstick and w/o emulsions lipstick were also developed as comparison.

\section{MATERIALS AND METHODS}

\section{A. Materials}

The materials used in this study were Olive oil, Tween 20 (Kao, Japan) and Span 80 (Biochem. which purchased from BRATACO, Indonesia. Cera alba, vaselin alba, cetyl alcohol, paraffine wax, methyl paraben, lanolin and aqudest were available at the Laboratory of Pharmaceutical Technology, Islamic University of Indonesia.

\section{B. Ternary Phase Diagram Construction}

W/O Olive nanoemulsions was prepared by PIC in high-temperature of $80^{\circ} \mathrm{C}$. Phase diagram of ternary 
which was comprised of water, a combination of surfactants, and olive oil in the ratio of volume $(\mathrm{mL})(1: 1$, 1: $2,1: 3,2: 3)$ was used to determine the effect of the concentration of the combination of surfactants, water and oil mixed in a vortex in a ratio (1: $1,1: 2,1: 3,1: 4$, 1:5, 1: $6,1: 7,1: 8,1: 9)$. The addition of oils into mixed of water and mixed-surfactants was ranging from $3 \%$ $78 \%$ of the total volume of oil with the addition interval at $\pm 5 \%$ to $100 \%$ [9]. At each addition of oil, the mixture was homogenized using magnetic stirrer in which the temperature $80^{\circ} \mathrm{C}$ [10]. At each addition of the oil phase, the mixture was visually observed as clear or cloudy. The area of w/o nanoemulsions was illustrated by constructing a ternary phase diagrams using software triplot 4.1.2. After the ternary diagram was formed, diagram with the largest area was then selected to arrange 3 series formulations of w/o olive nanoemulsions.

\section{W/O Olive Nanoemulsions Preparation}

From the largest area of nanoemulsions diagram, three series w/o nanoemulsions formulas with optimal water content were determined. The three formulas were evaluated their droplet size and polydispersity index and then further used as basic component of lipstick to form nanoemulsions lipstick.

\section{W/O Olive Emulsions Preparation}

$\mathrm{W} / \mathrm{O}$ olive emulsion were prepared to form emulsion lipstick as comparison for nanoemulsion lipstick. W/O olive emulsions were prepared with similar amount of water content as three series of w/o olive nanoemulsions but the amount surfactant was equal to their amount of water. The mixture (water/mixed surfactants/olive oil) was stirred by using ultra Turrax. Then, these w/o emulsions were further used as the basic component of lipstick to form emulsions lipstick.

\section{E. Evaluation of W/O Olive Nanoemulsions}

This evaluation is to characterize the w/o olive nanoemulsions and to investigate the effect of water content to characteristic of w/o nanoemulsions using low energy. Globule size and polydispersity index were determined using Particle Size Analyzer (PSA, Horiba SZ 100). PSA conditions for w/o nanoemulsions was set up as follows, the dispersing medium is olive oil with a viscosity of $1,367 \mathrm{cps}$ and the dispersible material is water with a viscosity of $1,313 \mathrm{cps}$. approximately $1 \mathrm{ml}$ sample was put into a cuvette and then inserted it to Particle Size Analyzer (Horiba SZ 100) and subsequently globule size and polydispersity index were measured.

\section{F. Lipstick Preparation}

Formulation of lipstick was modified from [11] lipstick preparation.

W/O olive nanoemulsions with different amounts of water was separately prepared from other ingredient in lipstick base formulation. Melting lipstick basis was based on the order of the melting point of each material, ie of the highest melting point to the melting point of the lowest, the melting sequence starting from the basic lipstick cera alba, vaselin alba, lanolin, paraffin wax, and cethyl alcohol. After all basic lipstick were perfectly melted and then the w/o olive nanoemulsions was added gradually and stirred the mixture to avoid hardening [11]. Lipstick base was poured into a mold and cooled into the freezer for 10 minutes, the temperature of the refrigerator is set $-2^{\circ} \mathrm{C}[8]$.

TABLE I. FORMULATION MODISIKASI LIPSTICK BASE NANOEMULSI WATER IN OLIVE $(\% \mathrm{~W} / \mathrm{W})$ MATERIAL

\begin{tabular}{lc}
\hline \multicolumn{1}{c}{ Ingredients } & Weight $(\mathrm{g})$ \\
W/O olive nanoemulsions* & 10.00 \\
Cera alba & 2.50 \\
Paraffin wax & 0.83 \\
Lanolin & 0.83 \\
Setil alkohol & 1.64 \\
Vaselin alba & 1.67 \\
\hline
\end{tabular}

*water content in w/o olive nanoemulsions was varied from the results of ternary phase diagram

\section{EVALUATION OF LIPSTICK}

\section{A. Hardness Test}

Hardness test was done to determine the strength of lipstick. Lipstick was held horizontally in approximately 0.5 inch from the edge of support. The weight was hung and gradually increased by 10 grams every 30 seconds until the lipstick was broken and weight was considered as hardness point. This procedure was conducted three times for each formulation [8].

\section{B. Spreadability Test}

Lipstick was spread over transparent glass in angle of $45^{\circ}$. The surface was observed and the picture was taken with dark background. Good spreadability was visualized from the smooth surface of lipstick when applied to the transparent glass (Anonymous, 1985).

\section{Melting Point Test}

Melting point of lipstick was determined by capillary tube method. Sample of lipstick was filled to capillary with 2.5-3.5 mm high. Capillary apparatus was heated up to approximately $10^{\circ} \mathrm{C}$ below the melting temperature of lipstick and the temperature was raised at speed of $1{ }^{\circ} \mathrm{C}$ per minute. Then the capillary was inserted to apparatus, and continued heating until the lipstick was completely melted. The melting distance was recorded. The above procedure was repeated for 3 replications for all formulations [12].

\section{Results Analysis}

Data obtained from both of nanoemulsions and lipsticks evaluation were shown as mean \pm SD. Data obtained were tested for normality using the ShapiroWilk or Kolmogorov-Smirnov, if the data were normally distributed $(\mathrm{P}>0.05)$, then continued with parametric test analysis of variance (ANOVA) with a $95 \%$ confidence level. 


\section{RESULTS AND DISCUSSION}

\section{A. Ternary Phase Diagram}

Table II contains the record of visual observation the mixture water: Mixed-surfactant, olive oil. Combination of two kind surfactant, tween 20 and span 80 , which mixed at elevated temperature $\left(80^{\circ} \mathrm{C}\right)$ at ratio $1: 1,1: 2,1: 3$ and 2:3 revealed HLB value in range of 7.4-10.5 which is able to form w/o emulsions [13]. The value of HLB plays role on distribution surfactant between the interfacial region and the oil phase [14], so that without cosurfactant, the combination of tween 20 and span 80 still formed a stable water in oil nanoemulsions. This result is consistent with other researchers results [10], [15], [16].
Combinations of surfactants and tween 20:span 80 were able to maintain the stability of the droplet by strengthening the interface layer rather than the use of a single surfactant [17]. The ability of the combination of surfactants to solubilize oil phase determined nanoemulsions area, compositions span 80 more resulted declining of interfacial tension of two immiscible liquids and the addition of tween 20 will further help in lowering the interfacial tension through increasing interface fluidity that forms a thermodynamically stable nanoemulsions [18]. Olive oil has long chain fatty acids that makes it more difficult to form nanoemulsions, but the use of quite high surfactants $(60 \%)$ will facilitate the formation of nanoemulsions [19].

TABLE II. Visual ObSERVATIOn During Oil Phase Titration For Pseudoterner Phase Diagram Construction

\begin{tabular}{|c|c|c|c|c|c|c|c|c|c|}
\hline $\begin{array}{c}\text { Ratio of water : mixed } \\
\text { surfactants } \\
\begin{array}{c}\text { Ratio of mixed surfactants } \\
\text { (Tween 20:span 80) }\end{array}\end{array}$ & $1: 1$ & $1: 2$ & $1: 3$ & $1: 4$ & $1: 5$ & $1: 6$ & $1: 7$ & $1: 8$ & $1: 9$ \\
\hline $1: 1$ & $\mathrm{NE}$ & $\mathrm{NE}$ & $\mathrm{NE}$ & $\mathrm{NE}$ & $\mathrm{NE}$ & $\mathrm{NE}$ & $\mathrm{NE}$ & $\mathrm{NE}$ & $\mathrm{NE}$ \\
\hline $1: 2$ & $\mathrm{E}$ & $\mathrm{E}$ & $\mathrm{E}$ & $\mathrm{E}$ & $\mathrm{E}$ & $\mathrm{NE}$ & $\mathrm{NE}$ & $\mathrm{NE}$ & $\mathrm{NE}$ \\
\hline $1: 3$ & $\mathrm{E}$ & $\mathrm{E}$ & $\mathrm{E}$ & $\mathrm{E}$ & $\mathrm{E}$ & $\mathrm{E}$ & $\mathrm{NE}$ & $\mathrm{NE}$ & $\mathrm{NE}$ \\
\hline $2: 3$ & $\mathrm{E}$ & $\mathrm{E}$ & $\mathrm{E}$ & $\mathrm{E}$ & $\mathrm{NE}$ & $\mathrm{NE}$ & $\mathrm{NE}$ & $\mathrm{NE}$ & $\mathrm{NE}$ \\
\hline
\end{tabular}

NE : Nanoemulsions

$\mathrm{E}:$ Emulsions
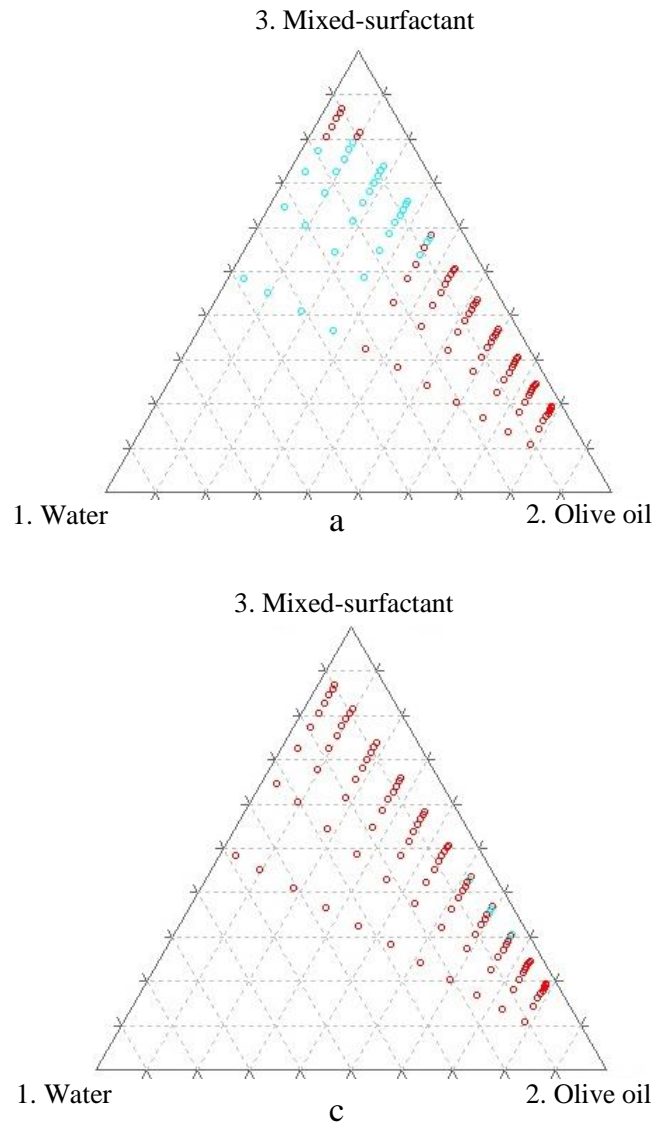

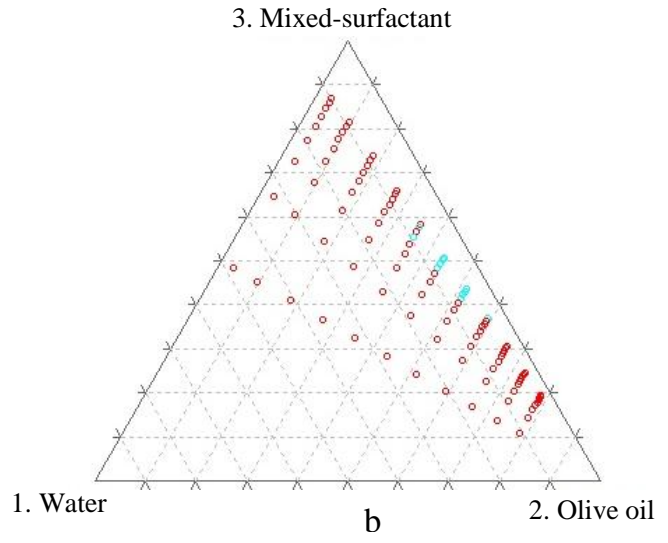

3. Mixed-surfactant

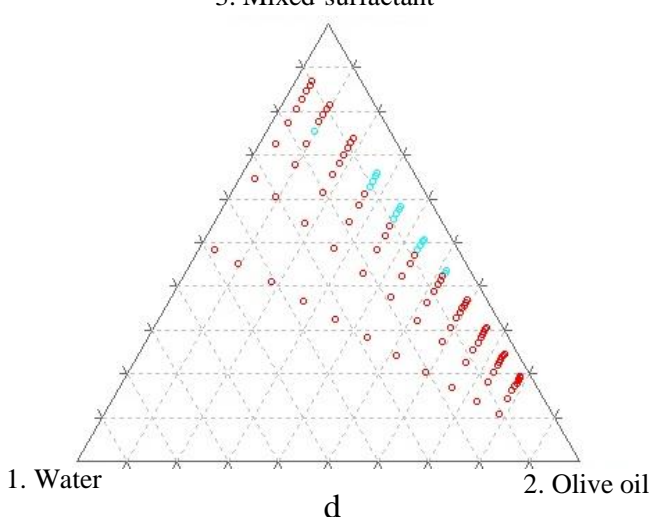

Figure 1. Pseudoterner phase diagram of water/mixed-surfactant (tween20:span80)/olive oil, a. tween 20:span 80 = 1:1, b. tween 20:span 80=1:2, c. tween 20 :span $80=1: 3$ and $d$. tween 20:span 80 . 
The visual observation marked in Table II was plotted on a pseudoterner phase diagram (Fig. 1) with 1, 2 and 3 axises representing the aqueous phase, oil phase, and a mixture of surfactants at a fixed volume ratio, respectively. In this figure, nanoemulsions points are plotted in blue dots and the emulsions points are in red dots. Fig. 1a, which contains mixture surfactant ratio at $1: 1$, shows the widest area of nanoemulsions than other figures. From this figure, 3 formulations of w/o olive nanoemulsions were formed with varied water content at 8,10 and $12 \%$ in fixed mixed-surfactants amount $(60 \%)$.

\section{B. W/O Olive Nanoemulsions Evaluations}

Fig. 2 shows the appearance of 3 formulations of w/o olive nanoemulsions. A clear and homogenous appearance with no separation was seen to all formulations and their replications. Nanoemulsions with a small globule size $(\mathrm{nm})$ that generate a transparent or clear, or slightly bubbly appearance is suitable for cosmetics industry, food or medicine [20].

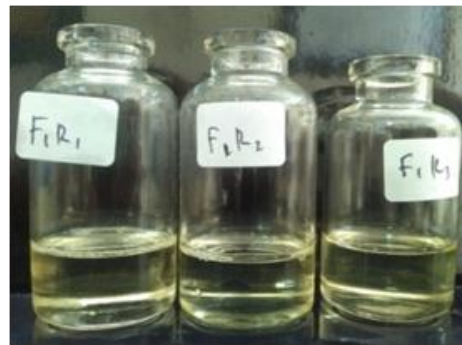

a

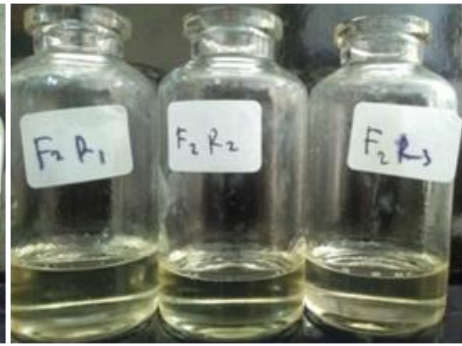

b

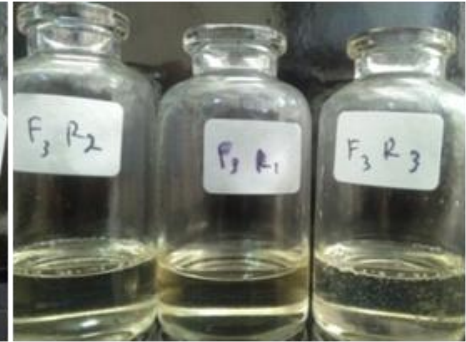

$\mathrm{c}$

Figure 2. Appearance of w/o olive nanoemulsions with different concentration of water at fixed concentration of surfactant $(60 \% 0)$, a. $8 \%$ water, b. $10 \%$ water and c. $12 \%$ water.

From the measurement results using the particle size analyzer without dilution, it is seen that the particles size ranged 29-31 nm (Table III), which is statistically, there is no significantly different between formulations. It is concluded that the different addition of water did not affected to particle size. The polydispersity index is also did not affected by the concentration of water.

TABLE III. PARTICLE SIZE AND POLYDISPERSITY INDEX OF W/O OLIVE NANOEMULSIONS

\begin{tabular}{ccc}
\hline Formulation & Particle size (mean \pm SD) $(\mathrm{nm})$ & Polydispersity index $(\mathrm{mean} \pm$ SD) \\
F1 & $29,33 \pm 5,30$ & $0,36 \pm 0,11$ \\
F2 & $30,23 \pm 7,33$ & $0,34 \pm 0,13$ \\
F3 & $29,83 \pm 11,47$ & $0,33 \pm 0,05$ \\
\hline
\end{tabular}

F1 : w/o nanoemulsions with $8 \%$ water, $60 \%$ mixed surfactant (tween 20 :span80=1:1) and 32\% olive oil F2 : w/o nanoemulsions with $10 \%$ water, $60 \%$ mixed surfactant (tween $20: \operatorname{span} 80=1: 1$ ) and $32 \%$ olive oil F3 : w/o nanoemulsions with $12 \%$ water, $60 \%$ mixed surfactant (tween 20 :span80=1:1) and 32\% olive oil

The particle size distribution graph in Figure 3 shows that all formulation of w/o olive nanoemulsions have one peak pattern (unimodal). It is indicated that the nanoemulsions has homogenous particle size distribution. The polydispersity index (Table III) also indicates narrow particle size distribution [21]. The less polydisperse particles also contributed their higher physical stability [22].
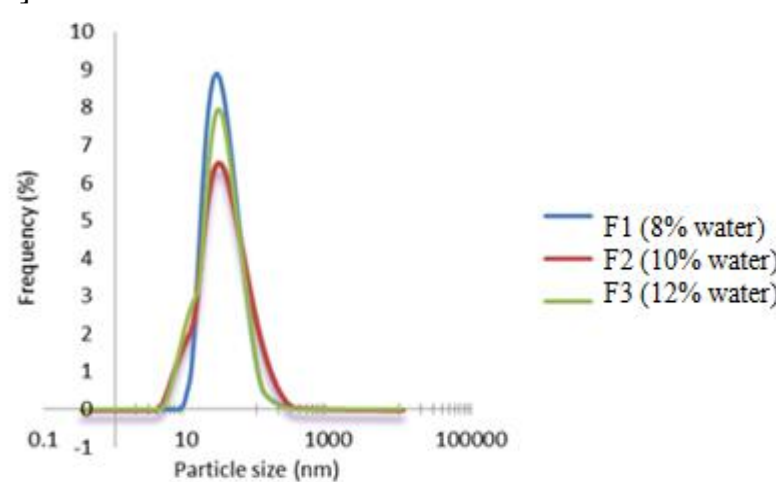

Figure 3. Graph of droplet size distribution of w/o olive nanoemulsions.

\section{Effect of Water Concentration on Physical Properties of Lipstick}

Table IV shows physical properties of lipsticks. It was shown that water content did not significantly change the lipstick hardness compared to conventional lipstick. Among nanoemulsions lipstick, increasing water content slightly increases the lipstick hardness. While among emulsions lipsticks, increasing water content did not significantly change the lipstick hardness. At highest water content $(12 \%)$, nanoemulsions lipstick is harder than emulsions lipstick but both are not significantly different compared to conventional lipstick. The low hardness of lipstick causes easily broken, cannot maintain its shape and difficulty in application [23], [24].

Melting point of lipstick also affected on lipstick preparation. The higher of melting point, the harder the preparation of lipstick [23], [25]. Stastistic analyses indicate adding water in both nanoemulsions and emulsions lipstick significantly change the melting point of lipstick compared to conventional lipstick except nanoemulsions lipstick with $8 \%$ water. Addition water in emulsions lipsticks raised the melting point compared to 
conventional lipstick and also nanoemulsions lipsticks. It is concluded that nanoemulsions lipstick could reduce some problems that left by addition water caused by higher melting point. Changing melting point of lipstick between nanoemulsions lipstick and emulsions lipstick might be led by changing crystalline behavior of lipstick components. It may be contributed by the amount of surfactant as Promduong and colleague found the different amount of surfactant affected to lipstick enthalpy [8].

TABLE IV. Physical Properties of Lipsticks

\begin{tabular}{llll}
\hline No & Formulations & Hardness (gram) & Melting point $\left({ }^{\circ} \mathrm{C}\right)$ \\
\hline 1. & Conventional Lipstick & $120 \pm 10,00$ & $49 \pm 0,00$ \\
2. & Nanoemulsions lipstick(8\% water) & $116,67 \pm 5,77$ & $49 \pm 0,00$ \\
3. & Nanoemulsions lipstick(10\% water) & $120,00 \pm 0,00$ & $47 \pm 0,00$ \\
4. & Nanoemulsions lipstick(12\% water) & $123,33 \pm 5,77$ & $45,0 \pm 0,00$ \\
5. & Emulsions lipstick(8\% water) & $126,67 \pm 5,77$ & $51,3 \pm 0,58$ \\
6. & Emulsions lipstick(10\% water) & $130,00 \pm 10,00$ & $51,3 \pm 0,58$ \\
7. & Emulsions lipstick(12\% water) & $116,67 \pm 5,77$ & $50,67 \pm 2,08$ \\
\hline
\end{tabular}

Fig. 4 shows the appearance of all lipsticks formulations and shown milky white color that comes from crystalline of paraffin wax. Conventional lipstick base has a hard texture and a little greasy, while emulsion lipstick has a hard texture on the trunk, but a little mushy. Nanoemulsions lipstick has a hard texture and a bit greasy than emulsions lipstick and conventional lipstick.
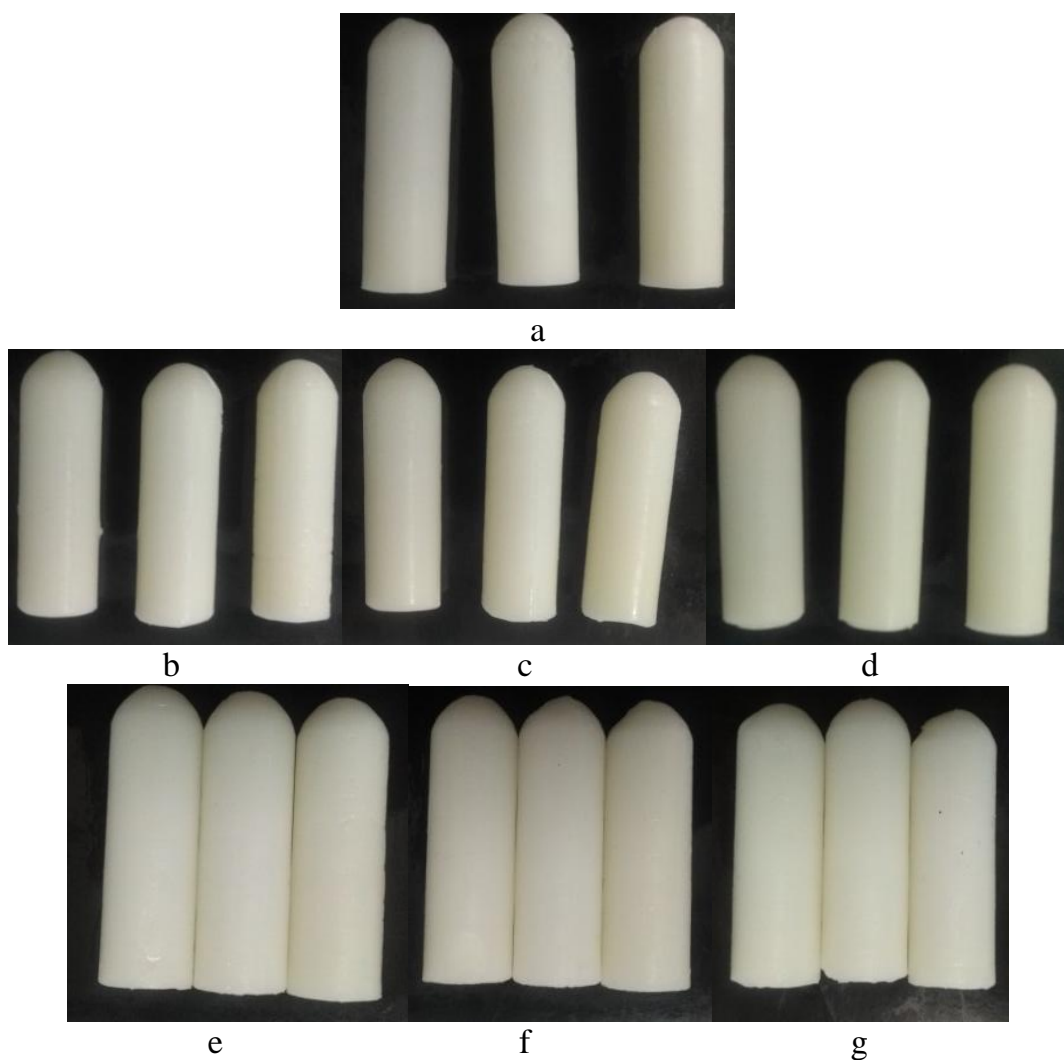

Figure 4. a. conventional lipstick; b. w/o olive nanoemulsions with $8 \%$ water lipstick, c. w/o olive nanoemulsions with $10 \%$ water lipstick, d. w/o olive nanoemulsions with $12 \%$ water lipstick, e. w/o emulsion lipstick with $8 \%$ water lipstick, f. w/o emulsion with $10 \%$ water lipstick, g. w/o emulsion with $12 \%$ water lipstick.

The presence of coarse grains or on the surface of the transparent glass gritty indicates that preparation of lipstick is not homogenous. From Fig. 5, it is observed that w/o nanoemulsions lipstick surface is smoother than emulsions lipstick and conventional lipstick. Emulsions lipstick is slightly rough surface, but the conventional lipstick is roughest indicating that the components of lipstick are not well dispersed. The presence of surfactants from nanoemulsions or emulsions may contribute to homogeneity of lipstick dispersion. 


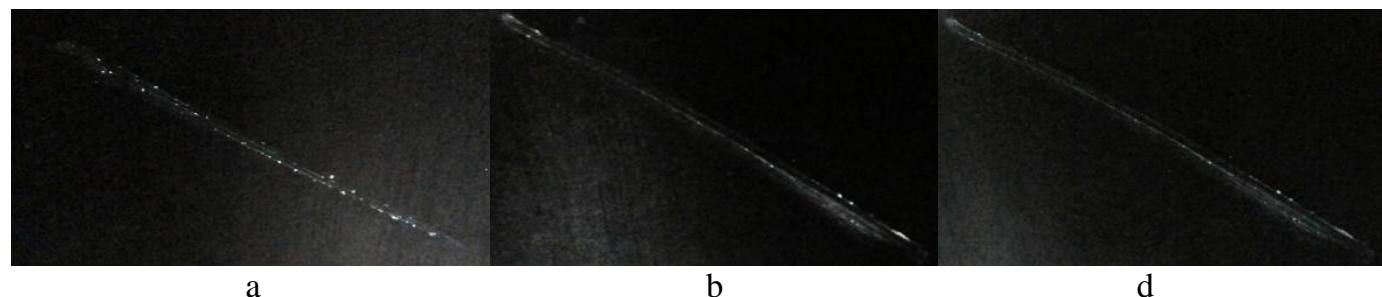

a

b

d

Figure 5. Surface of lipstick spreaded on transparent glass, a. conventional lipstick, b: w/o olive nanoemulsions lipstick (12\% water) and c. w/o olive emulsions lipstick (12\% water).

\section{CONCLUSIONS}

W/O olive nanoemulsions was successfully developed by low energy using mixed surfactant (tween 20: span 80) in equal ratio without co-surfactant. Water content significantly affected to lipstick melting point but not to lipstick hardness. In equal amount of water content, w/o olive nanoemulsions lipsticks have similar properties with conventional lipstick than w/o olive emulsions lipstick. It is concluded that w/o olive nanoemulsion can be developed as basis component of lipstick.

\section{REFERENCES}

[1] K. Kozlowski, "Read my lips: A cultural history of lipstick," Chronicle, p. 126, 1998.

[2] S. Abbas, J. W. Goldberg, and M. Massaro, "Personal cleanser technology and clinical performance," Dermatologic Therapy, vol. 17, pp. 35-42, 2004.

[3] S. Shaikh and K. Bhise, "Formulation and evaluation of medicated lipstick of allantoin," Asian Journal of Pharmaceutics, vol. 2, no. 2, p. 91, 2008.

[4] S. H. Majumdar and B. L. Kakadiya, "Desiging medicated lipstick for anti-fungal therapy," American Journal of Pharm Research, vol. 5, no. 2, 2015.

[5] B. L. Révérend, M. Taylor, and I. Norton, "Design and application of water-in-oil emulsions for use in lipstick formulations," International Journal of Cosmetic Science, vol. 33, no. 3, pp. 263-268, 2011.

[6] A. Beri, J. Norton, and I. Norton, "Effect of emulsifier type and concentration, aqueous phase volume and wax ratio on physical, material and mechanical properties of water in oil lipsticks," International Journal of Cosmetic Science, vol. 35, no. 6, pp. 613-621, 2013

[7] P. J. Dunphy, A. J. Meyers, and R. T. Rigg, "Cosmetic water-inoil emulsion lipstick comprising a phospholipid and glycerol fatty acid esters emulsifying system," U.S. Patent 5085856, February 4 1992.

[8] P. Promdouang, "Development of Water in Oil Nanoemulsion Lipsticks," M.S. thesis, Chulalongkorn University, 2010.

[9] S. Shafiq-un-Nabi, et al., Formulation development and optimization using nanoemulsion technique: A technical note," Aaps Pharmscitech, vol. 8, no. 2, pp. E12-E17, 2007.

[10] L. C. Peng, C. H. Liu, C. C. Kwan, and K. F. Huang, "Optimization of water-in-oil nanoemulsions by mixed surfactants," Colloids and Surfaces A: Physicochemical and Engineering Aspects, vol. 370, no. 1-3, pp. 136-42, 2010.

[11] L. Chabib, M. I. Rizki, and F. Hayati, "Formulasl nanopartikel karotenoid ekstrak wortel (daucus carrota I) sebagai pewarna IIlipstik," DPPM UII, pp. 809-822, 2011.

[12] A. A. Aher, S. M. Bairagi, P. Kadaskar, S. Desai, and P. Nimase, "Formulation and evaluation of herbal lipstick from colour pigments of Bixa orellana (Bixaceae) seeds," International Journal of Pharmacy and Pharmaceutical Sciences, vol. 4, vol. 5, pp. 357-359, 2012.
[13] P. M. Kruglyakov, Hydrophile-Lipophile Balance of Surfactants and Solid Particles: Physicochemical aspects and applications, Netherlands: Elsevier, 2000.

[14] V. Polychniatou and C. Tzia, "Study of formulation and stability of co-surfactant free water-in-olive oil nano- and submicron emulsions with food grade non-ionic surfactants," Journal of the American Oil Chemists' Society, vol. 91, no. 1, pp. 79-88, 2013.

[15] S. A. Yadav, D. Singh, and S. Poddar, "Influence of components of nanoemulsion system for transdermal drug delivery of nimodipine," Asian Journal of Pharmaceutical and Clinical Research, vol. 5, no. 3, pp. 209-214, 2012.

[16] V. Polychniatou and C. Tzia, "Study of the emulsifying ability of olive oil endogenous compounds in co-surfactant free olive oil w/o nanoemulsions with food grade non-ionic surfactants," Food and Bioprocess Technology, vol. 9, no. 5, pp. 882-891, 2016.

[17] N. Usón, M. J. Garcia, and C. Solans, "Formation of water-in-oil (w/o) nano-emulsions in a water/mixed non-ionic surfactant/oil systems prepared by a low-energy emulsification method," Colloids and Surfaces A: Physicochemical and Engineering Aspects, vol. 250, no. 1-3, pp. 415-421, 2004.

[18] Y. S. Elnaggar, M. A. El-Massik, and O. Y.Abdallah, "Selfnanoemulsifying drug delivery systems of tamoxifen citrate: design and optimization," International Journal of Pharmaceutics, vol. 380, no. 1, pp. 133-141, 2009.

[19] F. Shakeel and W. Ramadan, "Transdermal delivery of anticancer drug caffeine from water-in-oil nanoemulsions," Colloids and Surfaces B: Biointerfaces, vol. 75, no. 1, pp. 356-362, 2010.

[20] D. J. McClements, "Edible nanoemulsions: Fabrication, properties, and functional performance," Soft Matter, vol. 7, no. 6 , pp. 2297-2316, 2011.

[21] C. Lemarchand, P. Couvreur, C. Vauthier, D. Costantini, and R. Gref, "Study of emulsion stabilization by graft copolymers using the optical analyzer Turbiscan," International Journal of Pharmaceutics, vol. 254, no. 1, pp. 77-82, 2003.

[22] H. Mirhosseini, C. P. Tan, N. S. Hamid, and S. Yusof, "Optimization of the contents of Arabic gum, xanthan gum and orange oil affecting turbidity, average particle size, polydispersity index and density in orange beverage emulsion," Food Hydrocolloids, vol. 22, no. 7, pp. 1212-1223, 2008.

[23] N. Kamairudin, S. S. A. Gani , H. R. F. Masoumi, and P. Hashim, "Optimization of natural lipstick formulation based on pitaya (Hylocereus polyrhizus) seed oil using D-optimal mixture experimental design," Molecules, vol. 19, no. 10, pp. 1667216683, 2014.

[24] P. Shah, D. Bhalodia, and P. Shelat, "Nanoemulsion: A pharmaceutical review," Systematic Reviews in Pharmacy, vol. 1, no. 1, p. 24, 2010.

[25] A. O. Barel, M. Paye, and H. I. Maibach, Handbook of Cosmetic Science and Technology, CRC Press, 2014.

Siti Zahliyatul $\mathbf{M}$ is a junior lecturer of Pharmacy Department at Universitas Islam Indonesia, Yogyakarta, Indonesia. Her research interest is drug delivery systems especially on lipid based drug formulation. She had her bachelor degree from Faculty of Pharmacy, UniversitasGadjahMada Yogyakarta. And now she almost achieves her $\mathrm{Ph} . \mathrm{D}$ degree from Faculty of Pharmaceutical Sciences, Chulalongkorn University, Bangkok, Thailand. 